\title{
O PROCESSO DE PERCEPÇÃO DOS ESPAÇOS MARGINALIZADOS NO URBANO: O CASO DA FAVELA DO PAROLIN EM CURITIBA - PR
}

\section{The perception process of marginalized places in urban environments: the case study of the Parolin slum in Curitiba (PR)}

\author{
Helena Midori KASHIWAGI ${ }^{1}$ \\ Salete KOZEL ${ }^{2}$
}

\begin{abstract}
RESUMO
Este trabalho aborda a questão dos espaços marginalizados no urbano sob o enfoque da Geografia Humanística, utilizando como aporte teórico-metodológico a Fenomenologia para a abordagem do espaço. Esta leitura sobre o urbano busca identificar os valores culturais, sociais e afetivos do homem, consolidados pelas experiências e vivências. Nessa perspectiva, averiguamos o processo de percepção do espaço, enquanto lugar vivenciado, para se compreender o mundo vivido pelos moradores dessas comunidades marginais, numa visão interdisciplinar, instigando os planejadores urbanos à reflexão e ao amadurecimento dos próprios conceitos, frente às dificuldades e insucessos nos processos de intervenção urbana em ocupações irregulares.
\end{abstract}

\section{Palavras-chave:}

Fenomenologia, planejamento urbano, espaço vivido, mapas mentais, interdisciplinaridade.

\begin{abstract}
The article deals with the question of marginalized places in urban environments under a humanistic perspective in geography, making use of theoretical and methodological underpinnings from phenomenology to acess space. This reading of the urban space aims at identifying man's cultural, social and emotional values consolidated by experience and existence. Under this perspective, we have investigated the perception process of space as a lived space in order to understand the world experienced by the residents of this marginalized community from an interdisciplinary point of view, instigating urban planners towards a deeper reflection and a maturation of their own concepts when confronted with the difficulties and failures in the processes of urban intervention in irregular occupations.
\end{abstract}

\section{Key-words:}

Phenomenology, urban planning, lived space, mental maps, interdisciplinarity.

\footnotetext{
1 Arquiteta e urbanista - Companhia de Habitação Popular de Curitiba - Cohab - CT, Mestre em Geografia.

2 Professora adjunta Doutora do Departamento de Geografia da Universidade Federal do Paraná - UFPR.
} 


\section{INTRODUÇÃO}

O presente estudo busca, a partir da Geografia Humanística, em sua vertente fenomenológica, compreender o processo de percepção e apreensão dos espaços marginalizados no urbano, desvendando as relações espaciais simbólicas impressas pelos valores e sentimentos, redirecionando a abordagem do espaço em direção ao conceito de espaço vivido, lugar e território. A busca pela abordagem humanísticocultural surgiu da necessidade de se investigarem os constantes insucessos nos processos de intervenção urbana nesses espaços marginais, legalmente denominados de ocupações irregulares. Para o Poder Público é um desafio intervir nesses espaços informais e adequá-los as leis urbanísticas da cidade legal. Dentro deste contexto, o estudo de caso escolhido, a favela do Parolin, mostra-nos essa dificuldade de intervenção, pois, com quase 50 anos de existência, essa favela ainda apresenta características de pobreza e condições de vida subumanas, as quais contrastam com o entorno, que, ao longo desses anos, tornou-se uma área nobre e de alto valor imobiliário por ser próxima ao centro urbano. Diante dessa problemática, alguns questionamentos nortearam esta pesquisa, tais como: Por que os moradores resistem em deixar este lugar? Por que algumas dessas famílias, após serem reassentadas em loteamentos planejados, retornaram ao local onde viviam? Qual é o grau de afetividade dessas pessoas pelo lugar? Essas questões constituíram-se no cerne deste trabalho, pois despertaram a curiosidade de compreender o processo de percepção do espaço por esses indivíduos, contrapondo a visão do espaço vivido, sentido, do mundo percebido pelos moradores da favela, ao espaço concebido da cidade legal.

Este trabalho objetiva colocar em evidência a importância de novas abordagens no desenvolvimento de pesquisas na linha da Geografia Humanística e sua contribuição ao Planejamento Urbano, mostrando novos caminhos de olhar o urbano, sob a ótica interdisciplinar, $\mathrm{e}$, revendo o conceito de espaço, enquanto lugar e o redimensionamento do território a partir das representações cognitivas e as significações do espaço vivido. Salientamos que este artigo tem como base a dissertação de mestrado de Kashiwagi (2004), além de dois trabalhos anteriores, da mesma autora, publicados nos anais do VI Congresso Brasileiro de Geógrafos (2004) e do X Encontro de Geógrafos da América Latina (2005), cujo conteúdo se assemelha, mas difere em sua estrutura geral.

\section{ESPAÇO E LUGAR - FENÔMENOS DA EXPERIÊNCIA}

Ao abordarmos o espaço redirecionando-o ao conceito de espaço vivido, recorremos a Tuan (1983), o qual ressalta em seus trabalhos que, por meio da experiência, o significado de espaço freqüentemente se funde com o de lugar, sendo que o espaço é mais abstrato do que o lugar. Para o autor, o que começa como espaço indiferenciado transforma-se em lugar à medida que 0 conhecemos melhor e o dotamos de valor. Salienta que os arquitetos costumam falar sobre as qualidades espaciais do lugar; mas poderiam igualmente falar das qualidades locacionais do espaço. Isto é, as idéias de espaço e lugar não podem ser definidas uma sem a outra. Ressalta ainda que, na literatura específica, poucas obras tentaram compreender o que as pessoas sentem sobre espaço, lugar e paisagem, considerando as diferentes maneiras de experienciar (sensório-motora, tátil, visual, conceitual), e, interpretando os espaços e lugares como imagens de sentimentos complexos. Em sua obra Espaço e lugar, ele aborda temas relacionando o corpo aos valores espaciais, ao espaço mítico, destacando a relação entre tempo e lugar, ao espaço humanizado e a importância das experiências e subjetividades na constituição dos lugares. Essa obra contribui para as análises das diferentes maneiras como as pessoas sentem e conhecem o espaço e lugar, tendo como tema central o homem e como ele experiencia e entende o mundo (TUAN, 1983, p. 96-151).

Neste contexto, o mundo é composto por experiências pessoais, nas quais os lugares vividos são reforçados pelos mundos descritos na literatura, nas artes, na imaginação, na fantasia, contribuindo para a construção de nossas imagens sobre a natureza e de tudo que o homem constrói além de sua própria imagem. As experiências diárias vêm compor o quadro individual sobre a realidade, na qual todos somos artistas e arquitetos de paisagens, cujas lentes culturais e pessoais, de costumes e fantasias, permite-nos criar e organizar o espaço, tempo e causalidade, de acordo com nossas percepções e predileções. (MACHADO, 1999, p. 97-98)

De acordo com Konzel (2001), a idéia de lugar, relacionada apenas a localizações dos fenômenos no espaço físico, está cada vez mais distante, mas ainda corresponde a uma abordagem muito utilizada nos estudos geográficos. Destaca que o lugar encerra uma multiplicidade de relações, apresentando funções de uso determinados pelos ritmos de vida e formas de apropriação do espaço a partir de sua função social. Salienta, ainda que, muitos estudos têm focalizado a relação entre o espaço e o comportamento humano no ambiente, evidenciando os fundamentos cognitivos, afetivos e 
simbólicos como importantes indicadores para o lugar (Kozel, 2001 p.152-153). Dentre esses estudos estão os de Frémont (1976, p. 99-100), nos quais ele afirmava que

cada lugar significa uma combinação de elementos econômicos, ecológicos, sociológicos e demográ-ficos sobre um espaço reduzido, o lugar é visualizado como uma forma que se integra à paisagem local e regional. $\mathrm{O}$ que ele representa deve ser decodificado mais ou menos como uma linguagem, a linguagem dos homens falando com o espaço como meio de expressão.

O autor ressalta que a análise de ordem simbólica passa pelo estudo de tudo o que pode estar carregado de sentido, ou pelo estudo de tudo aquilo por onde as significações transitam.

A interpretação da experiência humana, com sua ambigüidade e complexidade, pode ser sistematicamente explorada para esclarecer o significado dos conceitos, dos símbolos e das aspirações, no que dizem respeito ao espaço, lugar e suas paisagens, mostrando como o lugar é um conceito e um sentimento compartilhados tanto como localização, como também meio ambiente físico (Machado 1999, p. 98-99). Neste sentido, a leitura dos espaço e lugares através das experiências, evidenciam a valorização do homem enquanto sujeito, buscando a relação do espaço e o comportamento humano no ambiente. Desta maneira, desvendando um mundo verdadeiramente percebido, construído sob os fundamentos cognitivos, afetivos e simbólicos do lugar.

\section{PERCEPÇÃO DO ESPAÇO ATRAVÉS DAS IMAGENS DO VIVIDO}

Nos trabalhos de Lynch (1997, p. 11-57), a percepção do espaço foi essencialmente fundamentada nas imagens visualizadas, as quais tinham como objetivo considerar a identidade e a estrutura de nossa imagem mental, demonstrando a importância da imaginabilidade no complexo meio urbano. O autor salienta que existem outras influências atuantes sobre a imaginabilidade, como o significado social de uma área, sua função, sua história, remetendo-nos a um espaço criativamente transformado pelos grupos humanos, que denominamos de espaço social. De acordo com Ferrara (1993, p. 234-236) o próprio conceito de espaço social, enquanto transformado ou em transformação pela ação de seus usuários, impõe um esforço interdisciplinar de diálogo entre as várias ciências que se ocupam do espaço social, no sentido de produzir não uma explicação, mas uma interpretação que se apóia em percepções sensíveis do espaço social, a fim de construir a sua inteligibilidade. A transformação do espaço social apreendida nas suas imagens constitui uma representação mediadora das explicações das demais ciências, pois se a imagem do espaço social é ilusória à luz da explicação científica, é real e objetiva como expressão concreta do espaço.

As imagens do mundo vivido resultam das experiências vividas no cotidiano e das representações de ordem simbólica, a qual não está ligada à racionalidade, da mesma forma que os comportamentos e as atitudes no espaço também não advêm dela. Para Gomes (1996, p. 323) o método de interpretação dessas imagens consiste em resgatar o sentido a partir daquilo que circula entre a esfera da ação e da representação, projetado sobre o espaço, no qual é preciso compreender o com-plexo código de signos e representações simbolizado no espaço. No pensamento de Tuan (1983, p. 179) o espaço ao contemplar simbolizações e signos adquire identidade e passa à condição de lugar, ou seja, a medida que o lugar é vivido pelo homem, as imagens são, gradativamente, construídas a partir das experiências. Essas imagens espaciais vividas, ao serem analisadas e interpretadas, permitem revelar as percepções do espaço.

\section{A FENOMENOLOGIA COMO MÉTODO DE ABORDA- GEM DO ESPAÇO}

Relph (1979, p. 5) acreditava ser a Fenomenologia um método de abordagem do espaço, o qual teria provado sua riqueza em outros domínios disciplinares ao revelar-se frutífero para o projeto humanista, que revaloriza aspectos esquecidos na Geografia tradicional. Essa metodologia baseada nos conceitos da Geografia Humanística em sua vertente fenomenológica, visa identificar os referenciais arquitetônicos e urbanísticos mais relevantes da área de estudo deste trabalho, consolidandose a partir da percepção dos moradores da favela e do entorno. De acordo com Merleau Ponty (2000, p. 64), a percepção que os outros têm do mundo deixa-nos sempre a impressão de uma palpação cega, de forma que a percepção do mundo pelos outros não pode entrar em competição com a de quem que está fora do contexto, ou seja, cada pessoa assimila de um modo e tem sua própria percepção do vivido. O autor destaca a importância de rever e redefinir as noções mais fundadas sobre o mundo, seja com novas palavras, empreendendo uma verdadeira reforma sobre o entendimento, evidenciando o homem que não mais se reconhece, convidando-o a pensar-se como enigma. $E$ ressalta "...ao mesmo tempo é verdade que o mundo é o que vemos e que contudo, precisamos aprender a vê-lo."

Segundo Relph (1979), a descrição e a interpretação fenomenológica do espaço oferecem métodos bem desenvolvidos para se realizar essa tarefa, e de modo 
algum duas considerações do método fenomenológico são semelhantes. Ressalta ele, ainda, que na perspectiva fenomenológica o homem e o mundo constituem uma unidade através de suas mútuas implicações, mas é a intencionalidade que fornece sentido ao mundo e somente através do exame dessas intenções poderemos tentar compreender esta unidade. Como exemplo, o autor destaca os trabalhos dos filósofos fenomenologistas John Wild (1963), Don Ihde (1973), e Herbert Spiegelberg (1975) nos anos 60 e 70, que oferecem breves considerações sobre descrições fenomenológicas. Para Wild (1963), "a habilidade para acompanhar imaginativamente os atos e atitudes dos outros é essencial a toda fase da pesquisa fenomenológica". Isto significa que, não envolve necessariamente idealismo e a recusa de nossas próprias experiências, "mas retroceder a elas e examiná-las com o que pode ser considerado semi-consciência não envolvida". Na visão de Idhe (1973), "antes de tudo, a intenção é descrever, não explicar, fenômenos da experiência imediata e estes incluem literalmente qualquer coisa experimentada, ou seja, lugar, silêncio, existência, contato interpessoal, etc". Contudo, para Spiegelberg (1975), faz-se necessário excluir as crenças nas explanações e considerações existentes e, igualmente, sobre os nossos próprios preconceitos, e tentar colocarnos na posição daqueles que estão experienciando o fenômeno. $\mathrm{O}$ autor destaca ainda que nesse processo de perda de significados para objetos, os significados originais do mundo vivido estão constantemente sendo obscurecidos por conceitos científicos e pela adoção de convenções sociais “...e apesar de vivermos nele, o mundo vivido não é absolutamente óbvio, e os seus significados não se apresentam por si mesmos, mas têm de ser descobertos". (RELPH,1979, p. 4)

Neste sentido, buscamos com essa pesquisa desvendar os significados ocultos no espaço vivenciado através da abordagem fenomenológica com o aporte de mapas mentais para interpretar o mundo vivido pelos moradores da favela. O olhar fenomenológico sobre o urbano permite-nos ver em sua essência o mundo subjetivo, onde o espaço adquire valores e revela uma outra realidade urbana.

\section{MAPAS MENTAIS - REPRESENTAÇÕES DO MUNDO VIVIDO}

A visão dos lugares, territórios, do mundo onde o homem vive é própria, e a representação deste mundo percebido advém dos símbolos, de uma construção mental decorrente da apreensão de significados, em que a razão não decodifica essas imagens. Estas imagens espaciais foram denominadas a princípio de mapas cognitivos, mapas conceituais e posteriormente mapas mentais. A partir da década de 60 , em busca de novas perspectivas de comunicação, houve a preocupação em desvendar essas imagens, e um dos pioneiros a associar a percepção do meio ambiente ao comportamento e ação humana, utilizando-se mapas mentais, foi o arquiteto americano Kevin Lynch. Os estudos de Lynch apoiaramse na psicologia e na antropologia, com o intuito de desvendar o que as pessoas percebem, direcionando-os para a avaliação do meio ambiente urbano e conseqüentemente para a qualidade visual das cidades (KOZEL, 2001, p. 208).

Esse arquiteto propõe uma metodologia voltada ao entendimento da forma visual urbana, em que a imagem é parte fundamental do equipamento humano, bem como para a vida, permitindo mobilidade intencional e exploração de novas formas de compreender as cidades. O conceito principal é a "legibilidade", que se resume na qualidade visual, identificando as particularidades de uma cidade. A imagem é um processo bilateral entre o observador e observado, e ele a integra a três componentes: identidade, estrutura e significado, onde a imaginabilidade tem o poder de evocar uma imagem forte. Para Lynch uma cidade legível é uma cidade imaginável (LYNCH, 1997, p. 7).

O termo carta mental foi introduzido aos estudos geográficos por Gould (1973), ao discutir o imaginário individual e coletivo relacionando a concepção de mundo. Para ele, os mapas mentais são imagens espaciais que estão na cabeça dos homens; não só dos lugares vividos, mas também dos lugares distantes, construídos pelas pessoas a partir de seus universos simbólicos, sendo estes produzidos através dos acontecimentos históricos sociais e econômicos divulgados. Nos estudos de Holvoet (1984) os termos geografia da percepção, percepção do espaço, imagem do espaço e cartas mentais foram reunidos e denominados de géographie mentale, pois esses termos não eram muito apropriados e limitavam a análise geográfica (KOZEL , 2001, p.144-145).

A autora ressalta que a tendência em investigar áreas cada vez menores torna as interpretações cada vez mais complexas por estarem ligadas ao comportamento humano, que ultrapassa os instrumentos de análise cognitivo-comportamentais. Ressalta ainda que, a partir desse entrave, alguns geógrafos buscam na Fenomenologia idealismo e existencialismo, suporte para as deduções, de onde surge o conceito de mundo vivido.

\section{O AMBIENTE PESQUISADO}

A área de estudo, conhecida por favela do Parolin, é uma ocupação irregular situada a apenas $4 \mathrm{~km}$ do centro, numa região privilegiada e de alta especulação 
FIGURA 1 - LOCALIZAÇÃO DAFAVELAE O CENTRO DE CURITIBA

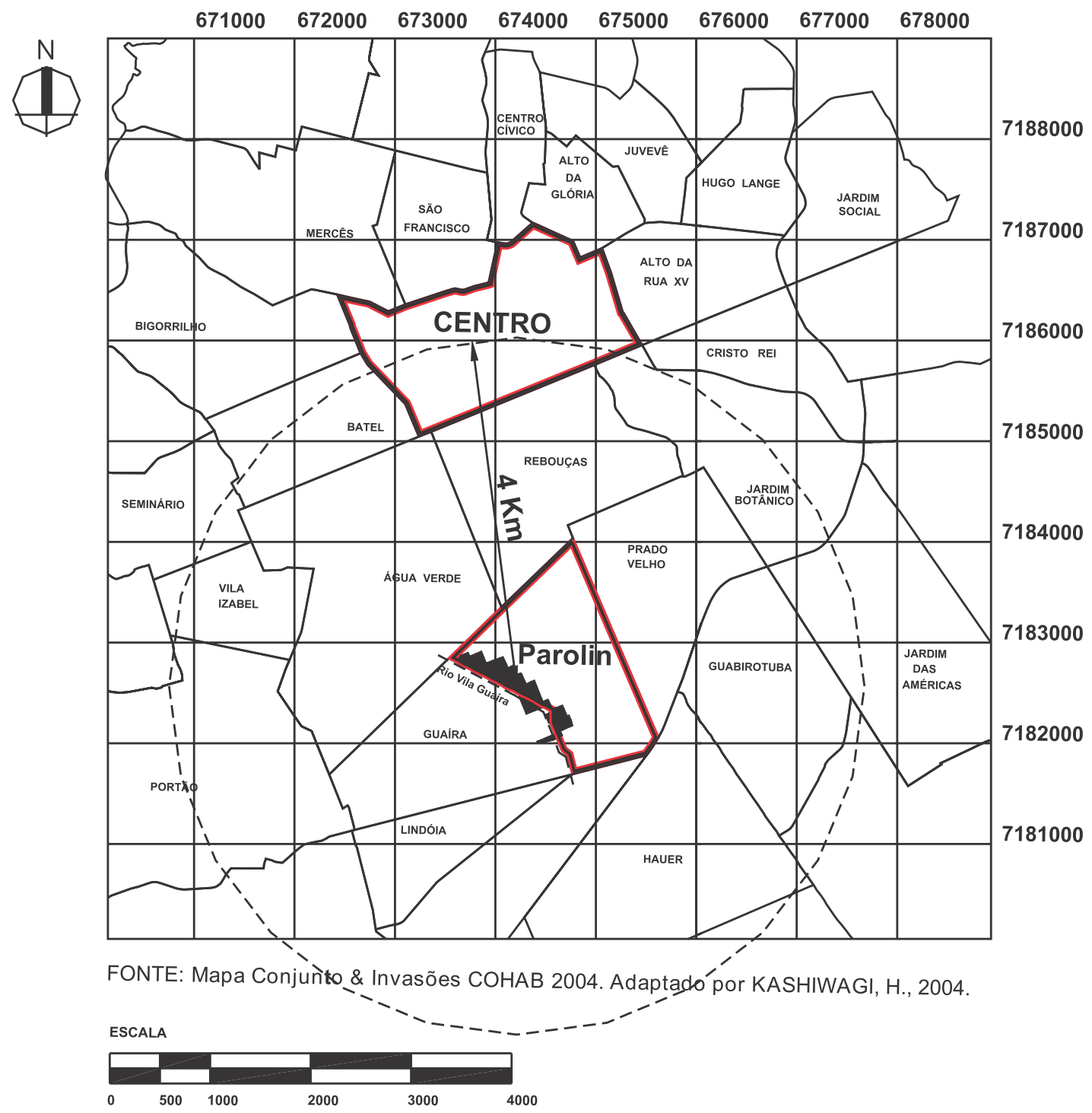

imobiliária. Segundo o último censo do IBGE (2003), a população é de quase 5.000 habitantes. A ocupação da maioria dos moradores é a de papeleiro, diarista, pedreiro, vigia. A localização central torna-se o principal obstáculo nas negociações para relocação das famílias, gerando forte resistência à intervenção no local, a qual implicaria na remoção e reassentamento de famílias em áreas distantes, disponibilizadas pelo Município (PMC, 1981).

Em 1940, surgiram as primeiras famílias no local, mas somente em 1960 a favela do Parolin adquiriu estrutura, com a chegada de diversas famílias vindas do interior do Estado do Paraná. Nessa época, o bairro do Parolin era uma área isolada, de puro mato, e rapidamente tornou-se alvo de ocupação. $\mathrm{O}$ adensamento gradativo consolidou essa favela ao longo do rio Vila Guaíra e ela hoje estende-se por áreas públicas, particulares e de fundo de vale. Essa favela é considerada uma das maiores e mais antigas áreas de ocupação espontânea da cidade de Curitiba (BOLETIM INFORMATIVO CASA ROMÁRIO MARTINS, 1997).

\section{O UNIVERSO DE ANÁLISE}

Neste estudo pretendemos mostrar através de pesquisa em campo, como a favela do Parolin é percebida e representada por três grupos. Os grupos são compostos por moradores da favela e não-moradores, que estabelecem parâmetros de comparação com a percepção do terceiro grupo, de planejadores urbanos. Buscamos investigar como o espaço da favela é percebido, apreendido e incorporado pelos indivíduos, quando são solicitados a 
representá-los, pelos mapas mentais, decodificando-os e explicitando os elementos urbanos essenciais dentro de um processo de intervenção urbana. $O$ trabalho empírico realizado em campo foi desenvolvido num período de dois meses, nos quais tivemos contato direto com os indivíduos que compuseram a amostra. $O$ grupo pesquisado integra o universo total de 40 indivíduos de diferentes faixas etárias, gêneros e situação socioeconômica. E, em direção à análise dos elementos provenientes da pesquisa, ressaltamos algumas características dos grupos.

- $\quad$ O grupo morador da favela caracterizou-se por indivíduos idosos e por aqueles nascidos na favela, composto por crianças, jovens e adultos, abrangendo um universo de 20 indivíduos.

- $\quad$ O grupo não-morador foi composto por 10 indivíduos, cuja principal característica era a proximidade com a favela: suas casas fazem divisa com os limites da favela e diferenciam-se pela legalidade do lote. Tal fato corresponde à importância do resgate com o passado.

- O terceiro grupo, planejadores urbanos, é com-posto de arquitetos, engenheiros civis e assistentes sociais, totalizando 10 profissionais, cuja principal característica é a atividade profissional relacionada com processos de intervenção urbana. Levou-se em consi-deração aqueles que já tiveram contato com a favela do Parolin, mesmo que de forma preliminar.

\section{METODOLOGIA DE ANÁLISE DOS MAPAS MENTAIS}

A metodologia adotada para análise e interpretação dos mapas mentais foi a desenvolvida por Kozel (2001) que tem como parâmetro a interpretação quanto à forma de representação dos elementos na imagem, distribuição dos elementos da imagem, quanto à especificação dos ícones (através da representação de elementos da paisagem natural, paisagem construída, elementos móveis e humanos) e por último a apresentação de outros aspectos ou particularidades. De acordo com a autora, o resultado da aplicação dessas interpretações nos mapas mentais desta pesquisa aliados a uma abordagem fenomenológica do espaço, revelam uma nova forma de abordagem que tem o intuito de contribuir nas análises espaciais, de forma a permitir compreensão da lógica dos atores, desde as aspirações individuais aos sistemas de valores dos grupos sociais.

\section{A) FORMA DE REPRESENTAÇÃO DOS ELEMENTOS NA IMAGEM \\ Numa primeira análise, Kozel (2001) observa que} há uma diversidade de formas nas representações, as quais identificou por ícones ou formas de representação gráfica através de desenho, letras, isto é, palavras complementando as representações gráficas e mapas, formas de representação cartográfica que evidenciam a espacialização do lugar. Assim, a partir dessa interpretação podemos observar em nosso estudo a predominância da letra em todos os grupos, também, no entanto, aparecendo associadas a ícones. É interessante destacar ainda que o grupo de moradores da favela, apesar do baixo grau de escolaridade, tem noção da espacialização do lugar, assim como os planejadores urbanos. Para melhor compreensão dessa análise, podemos observá-la através de alguns mapas mentais, exemplificados a seguir.

\section{MAPAS MENTAIS}

\section{EXEMPLOS DAS FORMAS DE REPRESENTAÇÃO DOS ELEMENTOS NA IMAGEM}

FIGURA 2-EXEMPLO DE ÍCONES E LETRAS

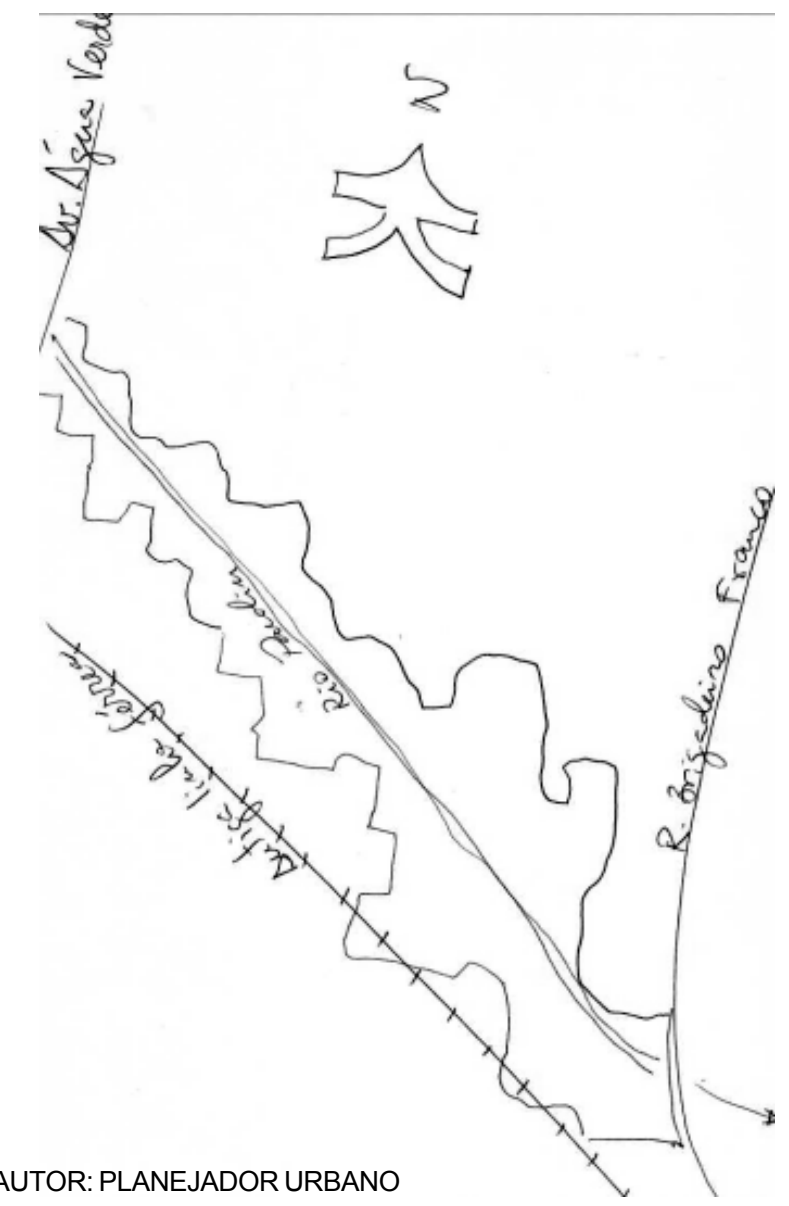


Neste mapa mental observamos a presença de ícones representando o perímetro da favela com forma irregular. Mostra sua localização central, ao representar imaginariamente o seu limite com vias principais. A representação da linha férrea, o rio e as ruas foram reforçadas pelas palavras.

\section{FIGURA 3-EXEMPLO DE ÍCONE E LETRAS}
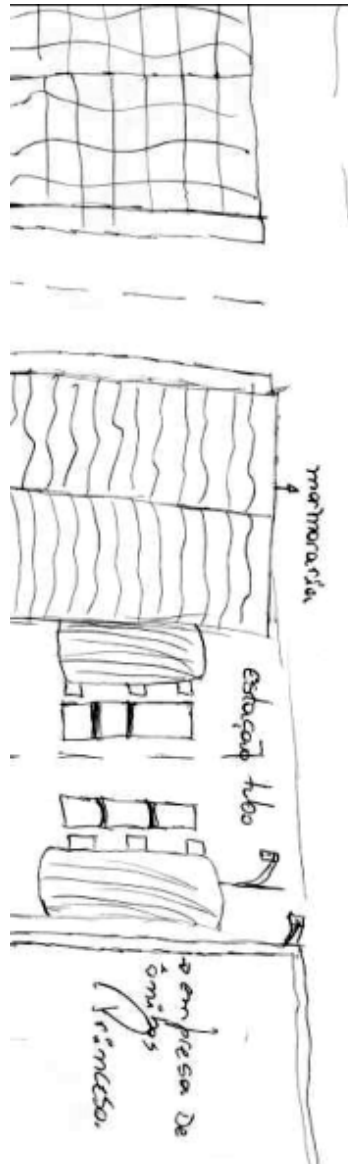

AUTOR: MORADOR DAFAVELA
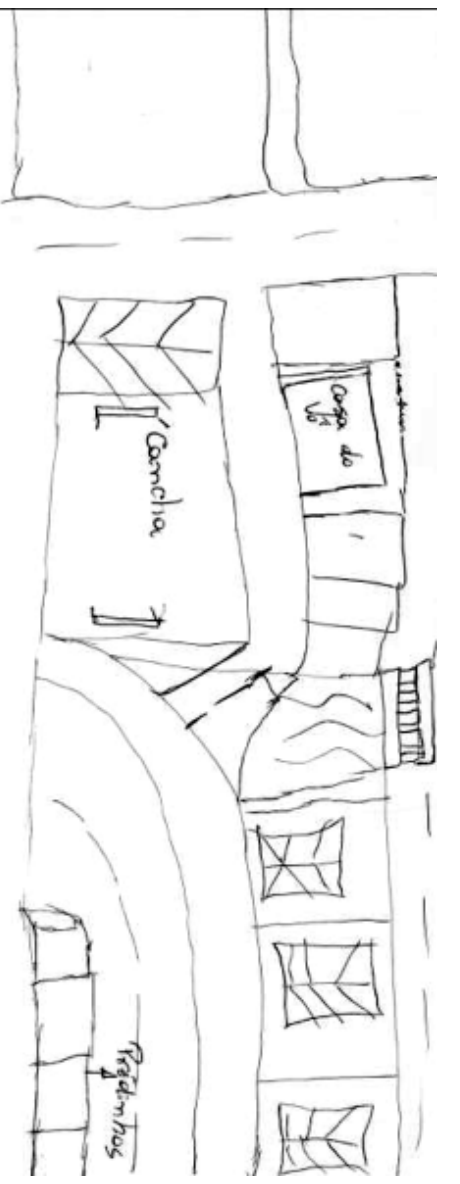

Neste mapa mental, observamos a representação do entorno da favela por ícones que destacam comércios, prédios, casas, empresa de ônibus, estações tubo, ponte, reforçados por palavras. Mostra um lugar com infraestrutura e serviços.

\section{B) DISTRIBUIÇÃO DOS ELEMENTOS DA IMAGEM}

Nesta interpretação, Kozel (2001) salienta que a partir da forma, verificou-se que as representações se diferiam também quanto à disposição da imagem, sendo assim identificados alguns aspectos que classificou:

- $\quad$ Representação da imagem em perspectiva;

- Representação da imagem em forma horizontal;
- Representação da imagem em forma circular;

- Representação da imagem em forma de quadros e quadras;

- Representação da imagem de maneira dispersa;

- Representação de imagens isoladas.

Ao aplicar esta interpretação no universo de análise, percebemos que a disposição da imagem em forma de quadras foi a que mais se destacou, com predominância nos grupos dos moradores da favela e os planejadores urbanos. Observamos ainda que a incidência das representações de imagens dispersas foi mais evidente no grupo dos não moradores. A representação em forma circular não foi verificada em nenhum dos mapas mentais dos grupos. Entretanto, as representações em forma horizontal, presente em todas os grupos, apareceram em maior predominância entre os moradores da favela. Nos mapas mentais a seguir, alguns exemplos dessas análises.

\section{MAPAS MENTAIS}

\section{EXEMPLOS QUANTO À DISTRIBUIÇÃO DAS IMAGENS}

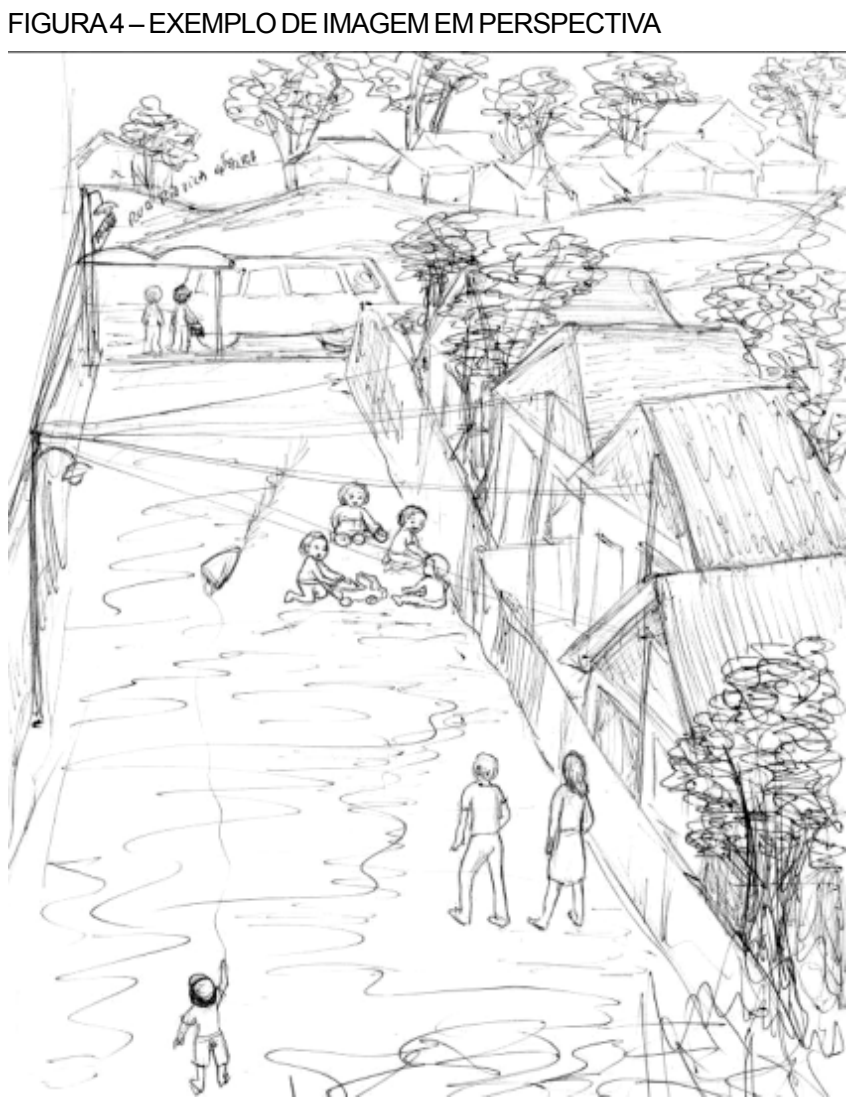

AUTOR: MORADOR DAFAVELA 
A representação da imagem em perspectiva nos mostra a rua como extensão da casa, usada para o lazer das crianças. Percebemos também a iluminação clandestina das casas, que evidencia a ilegalidade das construções. As casas amontoadas revelam a ocupação desordenada do lugar.

FIGURA 5-EXEMPLO DE DISTRIBUIÇÃO DA IMAGEM EM QUADRA

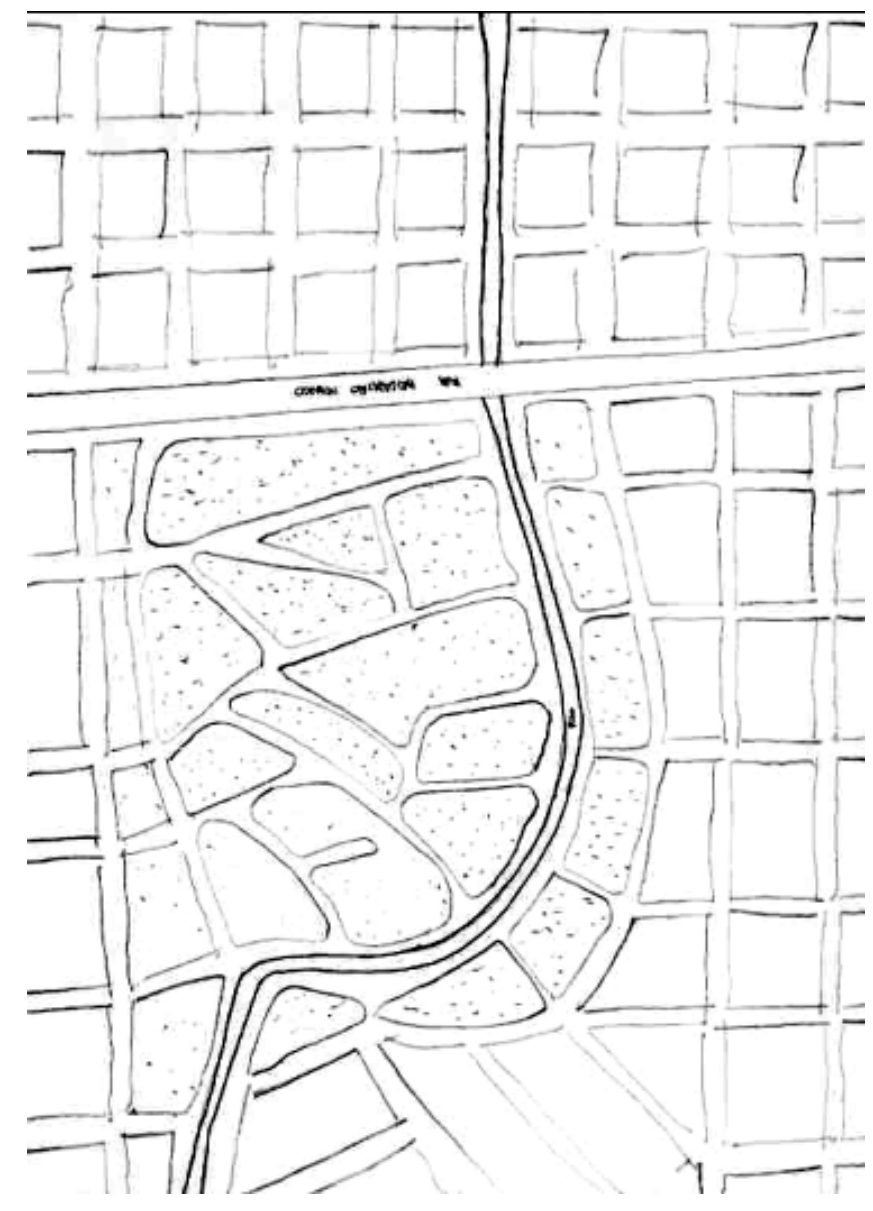

AUTOR: PLANEJADOR URBANO

Nesta imagem, percebemos a representação da favela organizada em quadras, evidenciando a inserção da favela na malha urbana. Observamos também a forma irregular e sinuosa das quadras da favela acompanhando a sinuosidade do rio em contraste com o traçado geométrico das quadras do bairro.
FIGURA 6 - EXEMPLO DE DISTRIBUIÇÃO DE IMAGEM DISPERSA

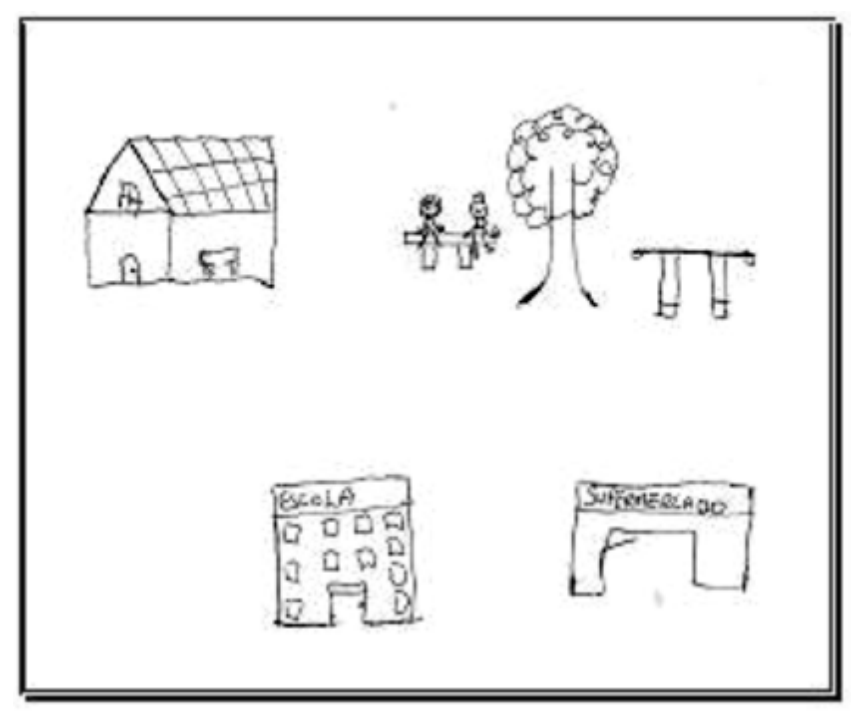

AUTOR: NÃO MORADOR DA FAVELA

\section{C) ESPECIFICAÇÃO DOS ÍCONES}

Nesta interpretação, além da interpretação quanto à forma e distribuição da imagem, Kozel (2001), a partir do olhar do mais simples ao complexo, com o intuito de detalhar ainda mais a análise, especificou os ícones que compõem as imagens em quatro grupos:

- Representando elementos da paisagem natural;

- Representando elementos da paisagem construída;

- $\quad$ Representação de elementos móveis;

- Representação de elementos humanos.

Usaremos como referencial o agrupamento feito por Kozel (2001). Todavia, alguns ícones citados por Kozel não aparecem nos mapas mentais deste estudo e mesmo assim eles cumprem sua função de exemplificar e orientar a análise dos mapas. Assim, o grupo definido pelos elementos da paisagem natural refere-se aos ícones inerentes aos elementos naturais existentes no ambiente, como montanhas, rios, lagos, sol, nuvens, flores e árvores em geral. Os elementos da paisagem construída relacionam-se ao tecido urbano construído pelo homem, ou seja, os prédios, igrejas, casas, barracos, praças, bancos de praça, parques, logradouros, pontes, calçadas, equipamentos esportivos (campo de futebol, pista de corrida, ciclovia, trilhas), também estão neste grupo os ícones representados por equipamentos industriais, comerciais (lojas, supermercados, motéis, correios, churrascarias, lanchonetes), equipamentos ligados ao transporte (ruas, estações tubo, terminais de ônibus), referenciais culturais (museus, universidades). O grupo 


\section{MAPAS MENTAIS}

\section{EXEMPLOS QUANTO À ESPECIFICAÇÃO DOS ÍCONES}

FIGURA 07 - EXEMPLO DE PAISAGEM CONSTRUÍDA

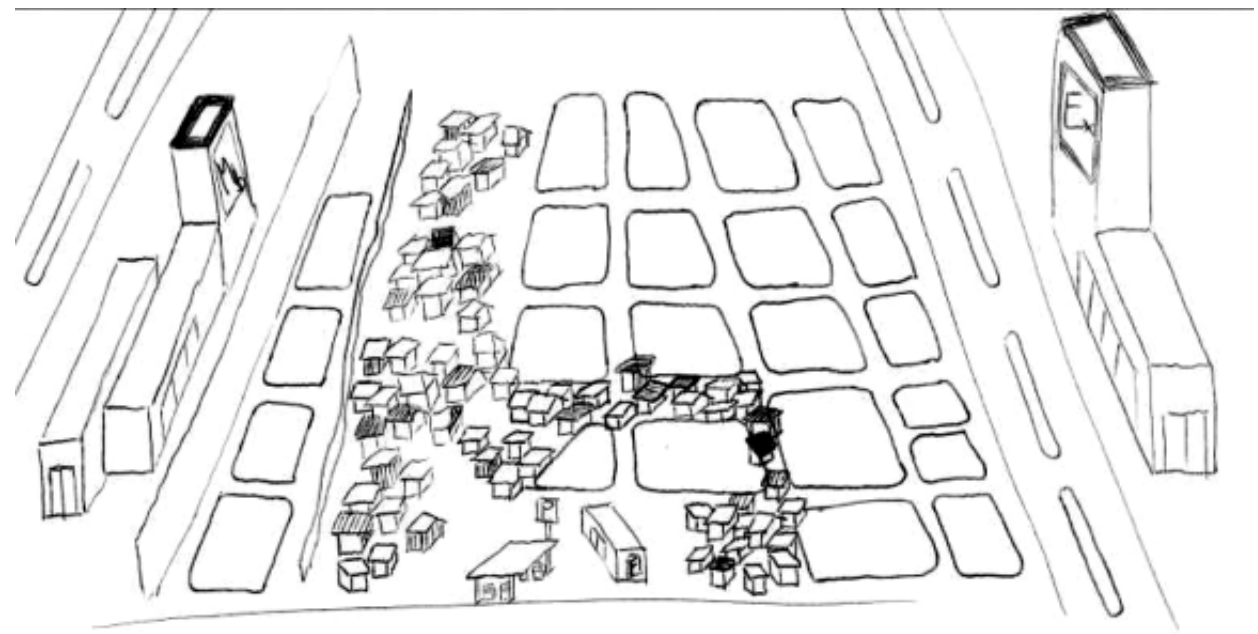

AUTOR: PLANEJADOR URBANO

Nesta imagem ficam evidentes as marcas do urbano no entorno da favela. A paisagem construída fica evidente na representação de shopping, supermercado, posto de gasolina, farmácia, e o traçado urbano das quadras e avenidas principais. Percebemos neste mapa as casas construídas sobre ruas, evidenciando a ocupação irregular.

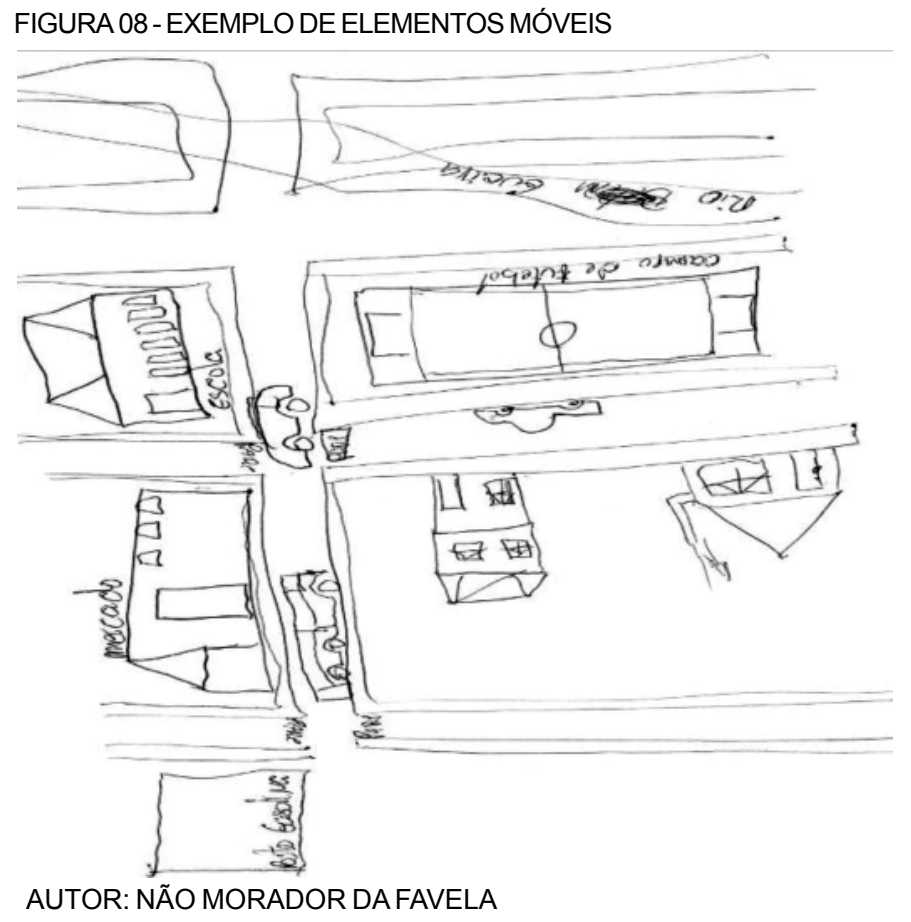

Os ícones representando os elementos móveis aparecem nesta imagem através de carros e ônibus. Mostra-se que o lugar apresenta uma dinâmica de comércio, serviços e lazer, inclusive sinalização de trânsito horizontal. 
dos elementos móveis relaciona-se aos meios de transporte como carros, ônibus, caminhões de lixo, bicicletas, barcos e aviões. E o grupo de elementos humanos refere-se à representação de crianças e pessoas mesmo que estilizadas.

\section{DESCOBRINDO OS SIGNIFICADOS DO URBANO POR MEIO DAS REPRESENTAÇÕES DO MUNDO VIVIDO}

Ao resgatarmos a identidade urbana de um lugar, interiorizando-nos no espaço particularmente vivido, sentido, percebido, desvendamos espaços de linguagens, evocações, sonhos e imagens. Deparamo-nos com um lugar de acontecimentos culturais e cenário de vivências, no qual o homem é o sujeito. Poderíamos dizer que a cidade é definida como a imagem de um mundo vivido, mas essa idéia se completaria dizendo-se que a cidade é também o contrário, ou seja, o mundo vivido, que lenta e coletivamente vai sendo construído e volta a construirse, incessantemente (SILVA, 2001).

As transformações no espaço ocorrem diariamente, surgem locais de referência, que se transformam em pontos de referência à medida que se tornam espaços de identificação e de expressão urbana, ou seja, à medida que esses locais relacionam-se com o homem pelos sentimentos e vivências. Dessa forma, o urbano da cidade se constrói. Cada cidade tem seu próprio estilo, cada bairro tem suas próprias características, cada vila tem sua identidade, assim como cada favela é diferente da outra. Essa diferença deve-se a um complexo conjunto de características, sejam ambientais, sociais, culturais, espaciais e locacionais. São essas características do lugar que levam os indivíduos terem imagens diferentes de outros moradores de outras favelas, bem como entre si, pois a formação mental de cada um deve-se às relações do meio em que vive e com si mesmo e a sua capacidade de abstrair do mundo real o que é visível em si mesmo.

Nesse sentido, percebemos, nas representações mentais, a imagem que cada entrevistado tem sobre o lugar, baseada em suas experiências e vivências no lugar. Essas imagens do vivido permitiram identificar, a partir dos resultados das interpretações dos mapas mentais, alguns elementos urbanos essenciais, relevantes aos processos de intervenção urbana. Esses elementos a que nos referimos são aqueles de natureza física - por exemplo, as ruas, a casa, o rio, a vegetação, as construções comerciais, a iluminação, o transporte coletivo, as quadras de esporte, etc. - e, numa escala maior, o traçado das quadras e a proximidade com o centro da cidade. Esses elementos desvendam a visão de cada indivíduo sobre o lugar e o grau de importância de cada um dentro do contexto urbano. Mesmo com pouca instrução ou conhecimento das leis urbanas, os indivíduos revelam, na representação mental, a verdadeira imagem do vivido. Nela, percebemos que $o$ silêncio e o medo dos moradores indicaram uma realidade de sonhos e de desejos. Percebe-se, então, que as imagens mostram as necessidades dos moradores e a plena consciência do lugar onde moram.

Uma intervenção urbana numa favela, iniciada a partir deste momento, no qual os desejos e os sonhos dos moradores são conhecidos, elevaria o homem a condição de sujeito nesse processo. Contudo, os aspectos físicos e legais são os principais determinantes nas práticas de planejamento urbano. Assim, esta pesquisa busca mostrar a importância do estudo do mundo vivido para se descobrirem os elementos urbanos de lugar e contrapor os seus valores aos do mundo concebido pela cidade legal.

QUADRO 1

\begin{tabular}{|c|c|c|c|c|c|c|}
\hline \multirow{3}{*}{$\begin{array}{l}\text { ELEMENTOS } \\
\text { ANALISADOS }\end{array}$} & \multicolumn{6}{|c|}{ PERCEPÇÃO DO LUGAR } \\
\hline & \multicolumn{4}{|c|}{ MUNDO VIVIDO E SENTIDO } & \multirow{2}{*}{\multicolumn{2}{|c|}{$\frac{\text { MUNDO CONCEBIDO LEGAL }}{\text { PLANEJ. URBANOS }}$}} \\
\hline & \multicolumn{2}{|c|}{ MORADOR } & \multicolumn{2}{|c|}{ NÃO MORADOR } & & \\
\hline FAVELA & Cidade & União & Banditismo & Medo & $\begin{array}{l}\text { Ponto de } \\
\text { Conflito }\end{array}$ & $\begin{array}{l}\text { Ocupação } \\
\text { irregular }\end{array}$ \\
\hline RIO & Lixão & Doença & Mau cheiro & $\begin{array}{c}\text { Boa } \\
\text { "lembrança" }\end{array}$ & Esgoto & Rio poluído \\
\hline RUA & Lazer & Esperança & $\begin{array}{c}\text { Comércio de } \\
\text { drogas }\end{array}$ & Insegurança & $\begin{array}{l}\text { Espaço de } \\
\text { convivência }\end{array}$ & $\begin{array}{c}\text { Acesso, } \\
\text { circulação }\end{array}$ \\
\hline MORADIA & Posse & Segurança & $\begin{array}{c}\text { Desvalorização } \\
\text { imóvel }\end{array}$ & Proteção & Identidade & Abrigo \\
\hline LOCALIZAÇÃO & $\begin{array}{c}\text { Garantia do } \\
\text { alimento }\end{array}$ & Sobrevivência & Privilégio & Economia & Estratégico & $\begin{array}{c}\text { Zona nobre, } \\
\text { central }\end{array}$ \\
\hline INTERVENÇÃO & Asfalto & Dignidade & $\begin{array}{l}\text { Remoção } \\
\text { favela }\end{array}$ & $\mathrm{Paz}$ & $\begin{array}{l}\text { Relocação das } \\
\text { famílias }\end{array}$ & $\begin{array}{c}\text { Verticalização } \\
\text { da área }\end{array}$ \\
\hline
\end{tabular}




\section{CONTRAPONDO O MUNDO VIVIDO E O MUNDO CONCEBIDO LEGAL}

Com base nas representações mentais e nas entrevistas de todos os indivíduos dos grupos de moradores, não moradores e planejadores urbanos, procuramos organizar e reunir as informações que mais incidiram no quadro 1.

Esse quadro visa associar a visão dos grupos sobre a percepção quanto à favela, ao rio, à rua, à moradia, bem como sua localização e sobre qual seria a intervenção adequada ao local. Elegemos esses itens por terem sido os mais apresentados nos mapas e discutidos durante as entrevistas. Dessa forma, temos duas colunas para cada grupo, para os moradores e não moradores: uma referindo-se ao mundo vivido e a outra, ao mundo sentido. Para os planejadores urbanos, a primeira coluna é o mundo real e a segunda é o mundo concebido e legal.

Aos planejadores urbanos questionou-se como percebiam e o que representavam a favela, o rio, a rua, a moradia, bem como sua localização e qual seria a intervenção urbana adequada ao local. Solicitou-se duas respostas para cada item, ou seja, devido à formação do grupo, a primeira resposta mostrou uma visão de um mundo concebido legal (concreto). Entretanto, a segunda resposta solicitada mostrou como aqueles itens eram subjetivamente representados, na tentativa de construir o mundo de sentimentos e qualidades, moldado por eles. A associação dessas informações mostra como as visões sobre um mesmo elemento contrapõem-se, bem como se complementam. De acordo com Goodey e Gold (1986), os estudos e as pesquisas da Geografia Humanística e da Percepção para a política de planejamento têm oferecido conhecimento inegável aos profissionais que atuam em desenho urbano e ao planejamento urbanoregional. Assim, ao alinharmos os significados, percebemos que, para se intervir num espaço e obter bons resultados, o conhecimento e compreensão da essência dos lugares é de fundamental importância.

Antes de iniciarmos esta análise, informamos que os nomes das pessoas dos grupos foram substituídos, de forma a preservar suas identidade. Assim sendo, o elemento "favela", para os moradores da favela, representa uma cidade que necessita de ruas, calçadas, pavimentação, iluminação pública, abastecimento de água e saneamento básico. Mas, ao mesmo tempo, ela representa união, como acredita Edivaldo, nascido na favela e desempregado, 29 anos: "Aqui a gente vive unido como se fosse uma pequena cidade. Quando um precisa de alguma coisa todo mundo ajuda". Nota-se que todos se ajudam, compartilham alimentos, alegrias e sofrimentos. Por outro lado, para o não morador da favela, na opinião de Marilena, zeladora de escola, 41 anos: "É o ninho de bandidos e maloqueiros". Essa opinião é complementada por Carmosina, do lar, 65 anos: "Não dá pra andar na rua com segurança". Ou seja, a favela transmite aos não moradores sentimento de medo e de insegurança ao caminharem pelas ruas do bairro. Já para os planejadores urbanos, essa favela é um ponto de conflito dentro da cidade, um entrave urbano de difícil solução e, do ponto de vista legal, é apenas mais uma ocupação irregular.

Quanto ao elemento natural "rio" (nesse caso o rio Vila Guaíra, em cujo entorno desenvolveu-se a favela), os moradores da favela deixaram claro nas entrevistas que o consideram como o "lixão", o que se confirma nas falas de Adonildo, papeleiro, 32 anos: "A gente separa o papel bom e o que não serve a gente joga no rio". Para Joseval, auxiliar de pedreiro, 39 anos: "Eu entendo dos tubos da casa, mas aqui a gente joga o esgoto no rio". Obviamente, devido a essa atitude, o rio representa foco de doenças, como reclama Silvicléia, do lar, 28 anos: "A gente não vence levar as crianças no postinho. Elas vivem doentes". Já para o não morador, o rio é referenciado com nostalgia, como o faz Lorival, vendedor aposentado, 68 anos: "Quando vim morar no bairro, há 22 anos, o rio era limpo, bonito de ver, tinha peixe, dava até pra gente banhar-se nele". Outra lembrança agradável é de Maria de Lourdes, do lar, 54 anos, "Era tudo campo, tinha muitas flores, nos dias quentes era bom... A gente brincava no rio". Apesar das boas lembranças, nos dias atuais, Maria de Lourdes tem opinião contrária sobre o rio: "Nos dias de calor, o rio tem mau cheiro, mesmo aqui em casa que é alto". Na mesma idéia, Elvira, aposentada, 73 anos, lembra: "Os da favela jogam lixo no rio e no verão o cheiro é insuportável". Para os planejadores urbanos, o rio representa o esgoto daquela favela e para as leis de preservação ambiental é um rio poluído, morto, mas cuja mata ciliar, mesmo assim, precisa ser preservada.

A "rua" para os moradores da favela é a extensão da casa, pois como não existe o quintal, a rua é usada como espaço de lazer, como relata Maria, do lar, 37 anos: "A gente não tem quintal, os barracos são tudo juntinho, daí as crianças brincam na rua", bem como para festas, conforme comenta João, vigia, 27 anos: "Quando alguém da vila vai casar, a gente fecha a rua e faz a festa de casamento; a gente não tem outro lugar, faz tudo na rua mesmo". A rua é palco de comemorações, mas além do lazer, a rua tem outro significado, o que ficou claro nos comentários de Edivaldo, 29 anos: "Todo mundo quer uma rua passando em frente de casa porque daí a gente tem um endereço". Para os moradores da favela ter uma rua passando em frente de suas casas representa a esperança de ter um endereço. Para os não moradores, a rua é o local de comércio de drogas, conforme delata Amarildo, pedreiro aposentado, 72 anos: "Seja de dia ou de noite eles estão ali nas esquinas vendendo as 'pedras"'. 
Maria de Lourdes, 54 anos, lembra: "Mandei meu filho pra casa da minha irmã lá no interior, porque um dos amigos dele vendia droga lá na frente do mercadinho". Essa atitude mostra a preocupação dela, quanto à vida e ao bem-estar de seus filhos, obrigando-os a morarem com parentes distantes. A rua também é, para os não moradores, um lugar inseguro, palco de tiroteios, assaltos, o que é lembrado amargamente pela senhora " $A$ ": "Naquele dia já tinha passado da hora da minha filha chegar, quando ela bateu na porta... Tava toda machucada... Não dá pra falar...". Jurandir, comerciante, 68 anos, previne com a experiência de quem mora a 48 anos no local: "Se a gente tá na rua à noite e estourar pipoca, a gente corre pra casa". Para os planejadores urbanos, a rua é considerada o espaço de convivência dos moradores e não moradores, mas que representa tecnicamente acesso, circulação e integração com a malha urbana.

A "moradia" é senão o principal elemento analisado, mas talvez o mais importante na vida dos moradores da favela, pois, para eles, ter uma casa é ter a posse sobre o lugar. Miriam, copeira, 39 anos, relembra: "Quando meu pai decidiu tentar a vida na cidade, viemos direto pra cá e rapidinho meu pai fez a nossa casa. Mais tarde casei e meu marido fez a nossa casinha do lado do meu pai... A gente não tem documento, mas também não sai daqui". O senhor " $H$ ", pai de Miriam, 71 anos, lembra que: "Lá na nossa cidade, no interior, um falou pro outro e muita gente veio pra cá. Os mais antigos pegaram os melhores lugares e fizeram suas casas. Os mais novos, dividem uma casa em duas, três, ou mais famílias". A casa, para os moradores da favela, representa a segurança de continuar no lugar. Contudo, para os não moradores, a moradia próxima à favela significa a desvalorização do imóvel e de difícil venda, observada por Maria de Lourdes, 54 anos: "Meu marido é doente, meu filho mora longe. Eu queria vender essa casa, mas é difícil". Isso causa certa imobilidade para quem vive próximo à favela. Marilena, 41 anos, lembra que: "Meu marido é caminhoneiro e a gente queria se mudar pra outra cidade, mas a gente ainda não foi porque é difícil vender a casa por ser perto da favela". Por outro lado, a casa é para eles ainda o lugar mais seguro, na qual se sentem protegidos, mas ainda vulneráveis à violência, como lembra Carmosina, 65 anos: "Eu moro há 45 anos aqui. Sempre ajudei as famílias da favela e, outro dia de manhã, ouvimos um barulho na sala e nos deparamos com um ladrão. Fiquei inconformada com a ingratidão deles. Agora quero me mudar daqui, mas quem é que vai querer comprar uma casa aqui, de frente pra favela?" Essa pessoa havia sido assaltada uma semana antes da entrevista. Talvez sua percepção sobre o lugar fosse outra antes do incidente. Já para os planejadores urbanos, a moradia é a identidade do lugar, o que caracteriza um bairro e representa legalmente uma construção, um abrigo.
A "localização" é, para os moradores da favela, a garantia do alimento, pois estando próximos ao centro, encontram facilmente sua fonte de renda, que é o papel. Muitos são catadores de papel, "papeleiros", e os vendem para grandes depósitos de papel, no próprio bairro. Adonildo, 32 anos, enfatiza: "Lá no centro tem bastante papel. Nos bairros tem pouco, por isso que é bom morar aqui. Quanto mais cato papel, mais certo é o pão lá de casa". Essa atividade garante a subsistência de muitas famílias. Lina, do lar, 25 anos, destaca: "Saio cedinho com meu companheiro e catamos o papel o dia inteiro. À noite separamos. O dinheiro que a gente tira é garantia da barriga cheia". Assim percebemos, diante de vários relatos, que a localização central da favela é a garantia do alimento e também da sobrevivência. Para os não moradores, a localização representa apenas a economia em passagem de ônibus. É, aliás, o que acha Marilena: "Eu e meu marido vamos a pé até o centro. É pertinho, dá uns 15 minutos. A gente acaba economizando. Pena que a favela desvaloriza o lugar". No entanto, a impossibilidade de se mudar do bairro gera um grande sentimento de impotência. Carmosina destaca: "Meu marido já morava aqui, eu vim depois que casei com ele. No início achava um privilégio, morar perto do centro, porque a gente economiza em tempo e gasolina, mas depois do assalto aqui em casa...". Para os planejadores urbanos, a localização é estratégica para futuros empreendimentos comerciais, e também uma zona nobre, devido à existência de construções de alto padrão. E por estar a apenas alguns quarteirões do centro da cidade, sua localização é extremamente central e privilegiada.

A "intervenção urbana" a que nos referimos é a benfeitoria feita pelo Poder Público no local, onde qualquer melhoria é uma intervenção. Assim, solicitamos, entre as várias necessidades, que elegessem a principal intervenção, o que não exclui a importância das demais. Para os moradores da favela, de maneira praticamente unânime, a intervenção mais importante para eles é o asfalto, que se sobrepõe à fome e à moradia, pois representa para eles a dignidade, os pés limpos, o progresso. Na opinião de Edivaldo, "O asfalto vale ouro e as pessoas recuperam sua dignidade. Elas até deixam derrubar seus muros, o que for, pra passar o asfalto, porque é muito ruim ter barro no sapato, quando a gente chega em casa". Para os não moradores, a melhor intervenção é a remoção total da favela, pois acreditam que só assim viveriam em paz. Opinião radical, mas diante dos assaltos à mão armada em plena luz do dia, muitos acreditam que a violência do bairro diminuirá se a favela for removida. É o que acha Viviane, professora, 34 anos: "Eu morei aqui, mas depois que casei fui pra outro bairro; venho na mãe só nos fins de semana, mas se removerem 
a favela, eu volto, porque a localização é boa". Para os planejadores urbanos, o ideal seria a realocação das famílias (temporariamente), ou seja, o mesmo desejo dos não moradores, mas com a diferença de se verticalizar a área e vender os imóveis para os moradores daquele lugar. Recentemente, foi publicada a proposta de verticalização da área por um grupo de arquitetos (DEUS, 2003), a qual prevê a construção de sete prédios de cinco e seis pavimentos, para posterior venda aos próprios moradores da favela. Segundo a mentora do projeto, Consuelo Cornelsen, "O desafio de todos esses arquitetos é pensar na moradia a partir do ponto de vista do ser humano, de uma pessoa que tem vontade, idéia e gosto. Não é porque é um favelado que vai pegar qualquer coisa. A nossa proposta é justamente pensar na moradia, e ter o favelado como um cliente é um grande desafio". Não é de interesse desta pesquisa prolongar essa discussão, mas apontar sobre essa intervenção urbanística, a idéia que "foi apresentada à Cohapar e imediatamente inserida no programa Direito de Morar (que objetiva regularizar e urbanizar favelas em todo o Estado)", mostra que o pensar mais humano está ainda fortemente apoiado na visão do urbanismo progressista.

Assim sendo, os moradores da favela deixam claro que pretendem permanecer onde moram, mesmo que haja a oportunidade de serem realocados para áreas urbanizadas, pois a história deles está naquele lugar. Dos aspectos positivos, o que mais se destaca, até mesmo para os não moradores, é a localização, pois em alguns minutos de caminhada estão no centro da cidade. Os moradores da favela acreditam que, na condição de "papeleiros", morando em áreas distantes não haveria como ganharem o sustento da família. Dos aspectos negativos, a falta de urbanização vem em primeiro lugar, pois urbanizar, em suma, engloba todos os serviços de infra-estrutura básica: água, luz, esgoto, arruamento, asfalto, etc. Outras características que levam esses moradores a resistirem e não deixarem o lugar, são a existência de shopping center, bancos, hipermercados, etc. Apesar de não terem condições de usufruir deles, sentem-se iguais aos outros. Nos bairros distantes, sentirse-iam longe da civilização.

Os não-moradores, ao contrário dos moradores da favela, deixam clara a vontade de deixar o lugar e também o desejo de que a favela nunca tivesse existido. Para eles, mesmo que a área venha a ser urbanizada, o bairro nunca mais será o mesmo. Os traumas são evidentes. Durante as entrevistas percebíamos a acolhida em seus lares para, após sentirem-se seguros, iniciarem a conversa. A maioria já sofreu algum tipo de violência e foram reveladas histórias de assaltos, assassinatos e estupros. Em meio a tristeza e muita dor, compartilhamos muitas histórias. Dos aspectos positivos, apenas a localização próxima ao centro foi apontada. Dos aspectos negativos, ressaltaram a própria existência da favela, os assaltos a qualquer hora do dia e da noite, os riscos de sair de casa e de caminhar na rua, mas principalmente a desvalorização do imóvel que os impossibilita de deixar olugar.

Os planejadores urbanos, do grupo entrevistado, vêem a Favela do Parolin como uma grande ocupação irregular sobre propriedades particulares e públicas, em que famílias invadiram a área e deixaram cicatrizes para o meio ambiente e a responsabilidade para o Poder Público de resolver seus problemas. Eles compartilham a mesma opinião dos não moradores, quanto ao aspecto positivo, pois a região é vista tanto pelos urbanistas como para os especuladores imobiliários como local para futuros grandes empreendimentos e de expansão do centro da cidade. Algumas palavras citadas durante as entrevistas resumem os aspectos negativos sobre esta favela: agonia, caos, morte, esgoto, conflito, perigo, sucata, cicatriz, isolamento e tumor. Essas palavras traduzem a favela como o ponto de conflito, que faz parte da cidade, mas se isola, que representa o caos urbano, a morte e a vida caminhando juntos, num contexto de perigo e agonia, cujo espaço, ao ser negligenciado, torna-se uma sucata urbana, que é a cicatriz e ao mesmo tempo o tumor da cidade.

\section{CONSIDERAÇÕES FINAIS}

Nesta experiência, buscou-se olhar o urbano sobre os aportes teóricos e metodológicos da Fenomenologia, de forma a encontrar uma nova abordagem do espaço e subsídios às práticas de planejamento urbano e às pesquisas na linha da Geografia Humanística. Esse método de análise espacial investigou o mundo vivido e percebido pelos moradores de uma comunidade marginal, a qual, de formas diferenciadas, se apropria do espaço. Novos olhares criam e recriam novas paisagens, invisíveis aos nossos olhos, mas que são reveladas através das experiências e vivências dos moradores. Compreender 0 processo de percepção dos espaços marginalizados no urbano é um desafio ao Poder Público, pois nem sempre as relocações de famílias e as intervenções urbanísticas culminam no anteriormente planejado. Acredita-se que a abordagem do espaço, caracterizada pelas experiências e vivências dos indivíduos, permite-nos decodificar e perceber os elementos sígnicos, os quais, aliados aos instrumentos legais de intervenção urbana, proporcionam uma melhor compreensão do espaço urbano.

O material reunido no trabalho empírico permitiunos desvendar os valores dos elementos urbanos e como estes interagem com a população. Os resultados obtidos 
estabelececem uma ligação consistente entre o teórico e o empírico que vão em direção à abordagem proposta. Esse método de análise espacial, baseado na experiência, é uma provocação ao planejamento urbano, cujo conhecimento fundamenta-se em conceitos legais. Entretanto, foi a partir dessas provocações que percebemos fendas no planejamento urbano, as quais pressupõem fragilidades nas leis, mas, ao mesmo tempo, mostram-nos possibilidades de penetração de novos conhecimentos, como, por exemplo, a abordagem proposta neste trabalho.

Essa ótica interdisciplinar sobre o urbano, respaldada na abordagem fenomenológica, possibilita-nos restabelecer o contato entre o mundo e as significações, na qual o conceito de lugar é valorizado ao ser interpretado enquanto espaço vivido, lugar encarnado de experiências e de aspirações dos seus ocupantes. Esse trabalho buscou ver o urbano sob um novo olhar, remetendo-nos, por meio do caminho da interdisciplinaridade, ao amadurecimento dos nossos próprios conceitos e à importância de reeducarmos nosso olhar.

\section{REFERÊNCIAS}

PAROLIN: o bairro na história da cidade. Boletim da Casa Romário Martins, Curitiba, Fundação Cultural de Curitiba, v. 24, n. 121, 1997.

DEUS, Sérgio Luis de. Favela com grife. Revista CREA-PR, Curitiba, ano 6, n. 26, p. 17-19, dez. 2003.

FERRARA, Lucrécia D’Alessio. Olhar periférico: informação, linguagem, percepção ambiental. São Paulo: USP, 1993.

FRÉMONT, A. La région, espace vécu. Paris: PUF, 1976.

GOODEY, B.; GOLD, J. Geografia do comportamento e da percepção. Belo Horizonte: Departamento de Geografia UFMG, 1986.

GOMES, Paulo César da Costa. Geografia e modernidade. Rio de Janeiro: Bertrand Brasil, 1996.

GOULD, Peter. On mental maps: image and environment. D. Stea., Chicago: R. M. Downs, 1973.

HOLVOET, M. Exemples d'estudes sur la géographie mentale. Journée des Chercheurs Société Géographique de Liège, Liège, mars 1984.

INSTITUTO BRASILEIRO DE GEOGRAFIA E ESTATÍSTICA. Censo demográfico 2000: Paraná e Santa Catarina. Rio de Janeiro, 2003. 1 CD-ROM.

KASHIWAGI, Helena Midori. O processo de percepção e apropriação do espaço nas comunidades marginais urbanas: o caso da favela do Parolin em Curitiba-PR. Curitiba, 2004. 169 f. Dissertação (Mestrado em Geografia) - Setor de Ciências da Terra, Universidade Federal do Paraná.

KOZEL TEIXEIRA, Salete. Imagens e linguagens do geográfico: Curitiba capital ecológica. Curitiba, 2001. Tese (Doutorado) - Faculdade de Filosofia, Letras e Ciências Humanas, USP.

LYNCH, Kevin. A imagem da cidade. Tradução: Jefferson Luiz Camargo. São Paulo: Martins Fontes, 1997.

MACHADO, Lucy Marion C. P. Paisagem valorizada: a serra do mar como espaço e lugar. In: RIO, Vicente del; OLIVEIRA, Lívia de (Org.). Percepção ambiental: a experiência brasileira. 2. ed. São Paulo: Studio Nobel, 1999. p. 97-98.

MERLEAU-PONTY, Maurice. Fenomenologia da percepção. Tradução: Carlos Alberto Ribeiro de Moura. 2. ed. São Paulo: Martins Fontes, 1999.

MERLEAU-PONTY, M. O visível e o invisível. Tradução: José Artur Gianotti e Armando Mora d'Oliveira. São Paulo: Perspectiva, 2000.

CURITIBA. Município. Prefeitura Municipal. Relatório das propostas de atuação em áreas faveladas do Município de Curitiba. Curitiba, 1981.

RELPH, Edward C. As bases fenomenológicas da geografia. Revista de Geografia da Unesp, Rio Claro, v. 4, n. 7,. p. 1-25, abr. 1979.

SILVA, Armando. Imaginários urbanos. São Paulo: Perspectiva, 2001.

TUAN, Yi-Fu. Espaço e lugar: a perspectiva da experiência. Tradução: Lívia de Oliveira. São Paulo: Difel, 1983.

Topofilia: um estudo da percepção, atitudes e valores do meio ambiente. Tradução: Lívia de Oliveira. São Paulo: Difel, 1980. 